\title{
Aplicación de técnica de cocción sous vide en productos cárnicos (solomillo).
}

Application of sous vide cooking technique in meat products (sirloin steak).

\author{
Alexia Vázquez Hernández ${ }^{a}$, Juan Ramírez Godínez ${ }^{b}$ Jair Emmanuel Onofre Sánchez ${ }^{c}$
}

\begin{abstract}
:
Cooking techniques and methods have had a lot of changes throughout history. From nouvlle cuisine, we look for lighter preparations where the flavors stand out. The sous vide technique created by Georges Pralus in 1974 has revolutionized the way of cooking. Vacuum cooking is a food cooking technique designed to maintain the integrity of the ingredients and their organoleptic qualities. This practice aims to present what are the advantages of applying this technique in meat foods, sirloin beef, where the product is packaged in an airtight packaging plus that cooking will be controlled only reaching the point of cooking.
\end{abstract}

\section{Keywords:}

Sous vide, temperature controlled, hermetic packaging

\section{Resumen:}

Las técnicas y métodos de cocción han tenido una gran cantidad de cambios a lo largo de la historia. A partir de la nouvlle cuisine, se buscan preparaciones más ligeras donde resaltaran los sabores. La técnica de sous vide creada por Georges Pralus en 1974 ha revolucionado la forma de cocinar. La cocción al vacío es una técnica de cocción de alimentos diseñado para mantener la integridad de los ingredientes y sus cualidades organolépticas.

Esta práctica tiene como objetivo presentar cuales son las ventajas de aplicar esta técnica en alimentos cárnicos, solomillo de res, donde se envasara el producto en un empaque hermético además de que la cocción será de manera controlada solo llegando al punto de cocción.

\section{Palabras Clave:}

Sous vide, temperatura controlada, empaque hermético

\section{Introducción}

En la búsqueda de diversas técnicas que mejoren las características organolépticas de la materia prima; se busca el sabor natural de cada ingrediente, nos invita a familiarizarnos con la esencia de textura, olor y color de la materia prima de cada platillo, dando pie a innovar con distintas técnicas de cocción, una de ellas es la cocina al vacío o sous-vide que se puede explicar como: "un método de cocción de alimentos diseñado para mantener la integridad de los ingredientes y sus cualidades organolépticas. La cocción al vacío consta de dos fases: por un lado, el envasado de los productos en bolsas herméticas, sin aire, mediante una máquina de cámara de vacío y, por otro lado, mediante la cocción de los alimentos, durante un período prolongado a relativamente temperaturas bajas" (fracademic.com, 2021)

Georges Paulus es quien crea esta técnica en 1974, siendo reconocido por grandes chefs de la época como Alain Ducasse, quien a la postre sigue transmitiendo estos conocimientos. Tony Botella en España, se ha dedicado

a Autor de Correspondencia, Profesor de la Licenciatura de Gastronomía, Universidad Autónoma del Estado de Hidalgo, https://orcid.org/0000-0001-6973-7009,Email: alexia_vazquez@uaeh.edu.mx

b Profesor de tiempo completo de la Licenciatura en Gastronomía, Universidad Autónoma del Estado de Hidalgo, https://orcid.org/00000001-7718-0546,Email: juan_ramirez@uaeh.edu.mx

c Profesor de tiempo completo de la Licenciatura en Gastronomía, Universidad Autónoma del Estado de Hidalgo, https://orcid.org/00000002-9484-8947 ,Email: jair_onofre6570@uaeh.edu.mx 
a su gran pasión, la cocina al vacío, tema sobre el cual ha impartido cursos y seminarios por todo el mundo, también ha escrito el libro Cocinar Al Vacío; en el cual menciona que ésta técnica de cocción, La cocina al vacío sigue siendo un método de cocción desconocido por la mayoría, dicha técnica reúne una serie de características y posibilidades que aumentan la calidad del producto, con un resultado final espectacular en cuanto a puntos de cocción, texturas, aromas o propiedades organolépticas, sin mencionar sus ventajas de conservación (Botella, Cocinar al vacío, 2010).

\section{Desarrollo}

a) Instrumentos necesarios

Máquina de vacío, cuchillo chef, tabla.

b) Nombre de la práctica

Cocción en sous vide de solomillo

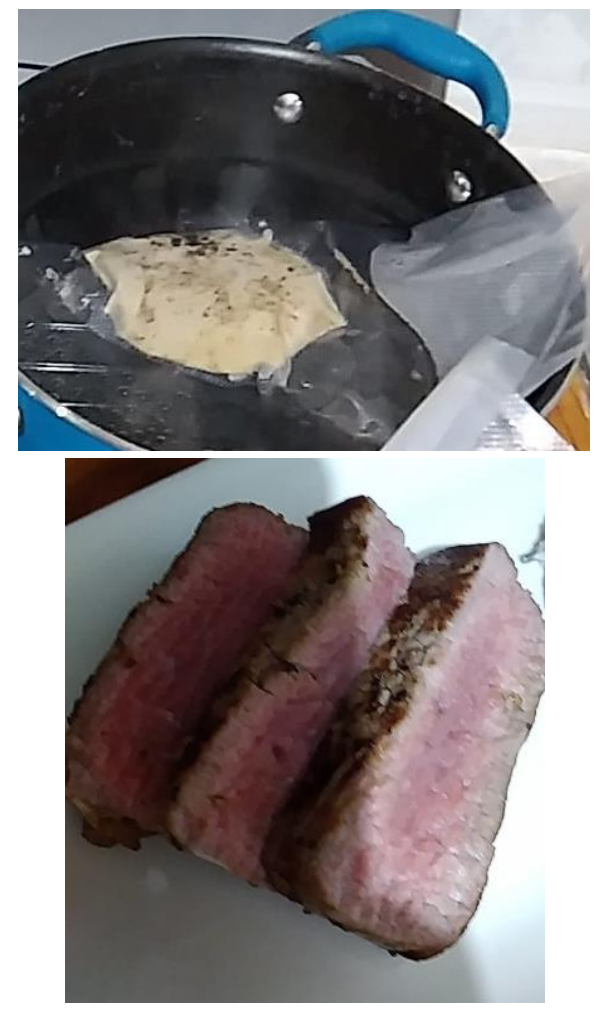

Imagen 1 y 2.Elaboración propia Solomillo. [4]

c) Insumos requeridos para su realización

Tabla 1. Insumos para realizar sopa de habas.

\begin{tabular}{l|ll} 
Ingredientes & Cantidad & Unidad \\
\hline Solomillo de res & 0.200 & $\mathrm{Kg}$ \\
Sal maldon & 0.002 & $\mathrm{Kg}$ \\
Pimienta negra & 0.002 & $\mathrm{Kg}$ \\
Aceite de oliva & 0.030 & $\mathrm{~L}$ \\
Agua & 0.250 & $\mathrm{~L}$ \\
Bolsa de vacio & 1 & $\mathrm{pza}$
\end{tabular}

d) Procedimiento

Mise and place

1. Pesar y lavar correctamente los ingredientes.

2. Sobre la tabla y con cuchillo chef limpiar el solomillo.

3. Salpimentar el solomillo y meter en la bolsa de vacío.

Procedimiento

1. Poner a calentar agua en un coludo hasta alcanzar $65^{\circ} \mathrm{C}$ (temperatura controlada todo el tiempo).

2. Una vez lista el baño se introduce el solomillo a $65^{\circ} \mathrm{C}$ por 15 minutos, sacar del baño y reservar 3 minutos.

3. Calentar un sartén con el aceite de oliva.

4. Sellar el solomillo y servir [4]

\section{Conclusión}

La técnica de cocción sous vide, por sus características sellado en bolsa de vacio evita que se pierda líquido y en consecuencia refuerza el sabor natural del producto cárnico, es una cocción tradicional se pierde hasta el 30\% del jugos durante la cocción, con este método se pierde el $10 \%$. Al tener una cocción controlada se da el punto exacto de cocción con una consistencia adecuada en cuando a la firmeza del producto se obtiene un producto mucho más suave y en consecuencia un alimento más deseable para el comensal.

\section{Referencias}

[1] Botella, T. (2010). Cocinar al vacío. En T. Botella, Ccoinar al vacío (págs. 1-304). Barcelona : AKAL.

[2] Botella, T. (s.f.). Creative Asignatures. Recuperado el 03 de 02 de 2121, de Creative Asignatures: https://docplayer.es/36958786-La-tecnica-dela-cocina-al-vacio-tony-botella-material-complementario.html

[3] Fracademic.com. (06 de 03 de 2021). fracademic.com. Obtenido de fracademic.com:

https://fracademic.com/dic.nsf/frwiki/1946481\#Biographic

[4] Roca, J. (2016). Cocción a abajas temperaturas. Barcelona, España: Planeta, S.A. 